\title{
A persuasão COMo "Psicagogia" SOB O PRISMA DE Górgias DE LEONTINO
}

Maurício Alves Bezerra Junior

\begin{abstract}
RESUMO
Existe uma ambivalência quando o tema são os Sofistas. A primeira visão é a que foi estabelecida por Platão, que fora depreciativa dos Sofistas, uma vez que o ateniense os coloca como algozes de Sócrates, o filósofo por excelência. Essa visão foi imperante durante quase toda a história da filosofia. Entretanto, desde Hegel, há estudiosos que procuram novo olhar sobre os Sofistas. Diante disto, é interesse deste artigo lançar esse segundo olhar sobre os Sofistas, utilizando como base um dos maiores expoentes, Górgias. Mostraremos que os sofistas tinham uma teoria do conhecimento prática e antropológica, utilizando a Persuasão para fazer uma psicagogia que conduzia os interlocutores. Mostraremos também, utilizando a obra de Platão, quais caminhos uma retórica deve traçar para lograr êxito, de acordo com Górgias.

Palavras-chave: Górgias de Leontino; Persuasão; Psicagogia.
\end{abstract}

\section{Persuasion as "PSychagogy" from the PERSPECTIVE OF GORGIAS FROM LEONTINI}

\begin{abstract}
There is an ambivalence when the theme is the Sophists. The first view is that established by Plato, who had been derogatory to the Sophists, since the Athenian places them as executioners of Socrates, the philosopher par excellence. This view has been
\end{abstract}

* Universidade Federal do Rio Grande do Norte - UFRN. Doutorando pela Universidade Federal do Rio Grande do Norte (UFRN). filosofiamauricio@hotmail.com

Revista Páginas de Filosofia, v. 9, n. 2, p. 15-17, jul.-dez. 2020 
prevalent throughout most of the history of philosophy. However, since Hegel, there are scholars who seek a new look at the Sophists. In view of this, it is in the interest of this article to take a second look at the Sophists, using as a base one of the greatest exponents, Gorgias. We will show that the sophists had a theory of practical and anthropological knowledge, using Persuasion to make a psychagogy that led the interlocutors. We will also show, using Plato's work, which paths a rhetoric must trace to achieve success, according to Gorgias.

Keywords: Górgias de Leontino; Persuasion; Psychagogy.

Ao nos debruçarmos sobre a história do pensamento filosófico, é comum nos depararmos frente a uma miríade de historiadores e comentadores da filosofia que colocam os sofistas como antifilósofos, como algozes daqueles que buscavam a verdade através do logos ( $\lambda \mathbf{o} \gamma \mathbf{o} \mathbf{s}$ ). Suas elucubrações seriam anódinas diante das preocupações dos filósofos. Essa ideia pungente é contingente do profícuo e tenaz gênio de Platão, filósofo grego que em seus profusos textos constituiu a imagem paradigmática dos sofistas, enquanto adversário. Imagem essa que fora reproduzida por boa parte dos estudiosos da história da filosofia ${ }^{1}$. Dentre esses, vemos a figura de Heinrich Gomperz (2005 apud CASSIN, p. 13), que escreveu um artigo no qual afirma que a sofística sequer faz parte da história da filosofia, mas sim, da história da retórica, desqualificando as obras de sofistas como Górgias de Leontino, destituindo-o de qualquer trono do saber e situando-o como uma "farsa"; seguindo e sedimentando a imagem adornada pelo corpus platônico.

Entretanto, outros estudiosos helenistas têm se debruçado com o escopo de compreender a importância dos sofistas para a sociedade grega antiga, principalmente no cenário democrático que Atenas vai viver em idos do século V a.C². Pesquisadores como George Briscoe Kerferd,

1 É mister apontar que na clássica obra de Diôgenes Laêrtios, Vidas e Doutrinas de Filósofos Ilustres, que visa a contar parte da história e do pensamento dos gregos clássicos, o autor versa sobre apenas um sofista: Protágoras. Ainda assim, está engendrado pelo pensamento desenvolvido por Platão sobre o sofista.

2 Importante observar que haverá uma voz destoante do paradigma estabelecido por Platão já na filosofia idealista de Hegel, uma vez que o filósofo alemão atesta a importância dos sofistas para com a história da filosofia. Kerferd (2003, p. 14) 
em seu importante livro O Movimento Sofista; Barbara Cassin, em seu estudo $O$ Efeito Sofístico; Mario Untersteiner, em seu texto A Obra dos Sofistas: uma Interpretação Filosófica; William Guthrie, em sua obra Os Sofistas; e o trabalho ubíquo de Werner Jaeger, Paidéia: a Formação do Homem Grego constituem insumos de lauta produção para revermos o papel dos sofistas na cultura grega. Ancorado nas obras supracitadas - além de outras a serem expostas abaixo -, é escopo deste artigo estudar os sofistas e sua prática retórica, pontuando sua relevância para a pragmática da persuasão e focando em um dos maiores expoentes, a saber, Górgias de Leontino. Intentamos, também, refletir sobre quais os caminhos que o Leontino afirma ser necessário perfazer e observar para se ter uma persuasão eficaz, que conduza a uma psicagogia - condução da "alma". Partiremos dos estudiosos acima para recolocar o sofismo no lugar que lhes faz justiça: na filosofia. Ademais, não é nosso propósito desconsiderar o corpus platônico, visto que o mestre ateniense constitui fonte necessária para a compreensão do período e das ideias de Górgias. Por isso, se faz mister neste artigo a utilização do diálogo Górgias, em que Platão coloca o Leontino como algoz argumentativo de Sócrates, seu personagem sempre principal ${ }^{3}$. Ainda, observaremos como a retórica e a persuasão (ПєıӨஸ́), esta aduzida por Górgias como força assaz pungente para a condução das pessoas em ambiente público, fazem parte da pragmática democrática de então, revelando-se uma "psicagogia", ou seja, como condutora das almas.

Os sofistas devem ser considerados pensadores que surgiram em um momento necessário, pois eles representam a refutação da abstração do ser eleático, que Platão dá continuidade, pela consideração das coisas efetivas, do mundo sensível, plural, de movimento e subjetivo

aponta sobre isso: "Hegel via a história da filosofia como um desenrolar progressivo da mente Universal"; e que "[...] Todo o movimento do seu pensar segue um padrão universal: primeiro uma tese surge e é contraposta a uma antítese, de ambas se extrai uma síntese" (KERFERD, 2003, p. 17). A partir da perquirição de Hegel, adotou-se a ideia de que os sofistas tinham uma relevância destacada para o desenvolvimento da filosofia, abrindo margens para os estudos mais detalhados desse movimento, por parte de alguns estudiosos.

3 As citações do Górgias utilizadas neste artigo são retiradas da tradução em língua portuguesa de Daniel R. N. Lopes (2011). 
(CASSIN, 2005). Corroborando com essa ideia, nos diz Kerferd (2003, p.72): "Para [os sofistas], o ponto de partida é o próprio mundo fenomênico, regularmente considerado como constituindo todo o real e, consequentemente, como único objeto possível de conhecimento". Guthrie (1995, p 25), por seu lado, afirma que "[...] se os sofistas foram produtos de seu tempo, por sua vez também ajudaram a cristalizar suas ideias. Mas seu ensino pelo menos caiu em terreno bem preparado". Vemos assim que os sofistas ofereceram as primícias do pensamento antropológico, sendo antiplatônicos antes mesmo de Platão, uma vez que voltavam suas preocupações para o homem enquanto ser fenomênico e social, não buscando conhecimento para além do mundo sensível. Ainda sobre isto, podemos observar o comentário de Mario Untersteiner (2012, p. 22-23):

Os sofistas coincidem com uma concretude anti-idealista que não segue o caminho do ceticismo, mas sim aquele de um realismo e de um fenomenismo que não detêm a realidade dentro de um esquema dogmático porque, ao contrário, deixam-na fremir em todas as suas antíteses, em toda a sua tragicidade, em toda a imparcialidade imposta por uma cognoscibilidade que despertará a alegria da verdade.

Muitos problemas aparecerão tratados de modo insuficiente pela sofística. 0 pensamento tem ainda diante de si um longo caminho. Mas permanecerá o mérito dos sofistas por terem concedido ao homem vida, palavra e pensamentos humanos.

Atestada a relevância dos pensadores sofistas, podemos nos perguntar: Por quê esses pensadores confluíram, sobretudo, para a cidade de Atenas no século V a.C.? Pois é de sapiência universal que a característica comum dos sofistas era que eles eram nômades, sempre de cidade em cidade oferecendo seus serviços em troca de pagamento. De acordo com Kerferd (2003), o que propiciou a passagem de boa parte dos sofistas na Atenas do século V a.C. foi a condição social e política que demandava na cidade desde Sólon. A ideia democrática grega, que denotava o poder emanado do demos e que os cargos de conselhos deveriam ser comandados pelos mais competentes, fora assaz relevante para estimular o interesse dos sofistas vindos de vários lugares com o intuito de oferecer os seus atributos de ensinar 
sua incrível oratória e estimular a capacidade de persuasão, tão caras aos homens que visavam engendrar na política. Concomitantemente a esse fenômeno político de Atenas, temos a pessoa do grande orador e político Péricles (495-429 a.C.), um ícone da Era de ouro de Atenas que sempre se mantivera próximo dos que se chamavam de sábios. Coabitava no círculo de Péricles justamente o maior dos sofistas, Protágoras, que já se intitulava de "sofista", visto que outros preferiam não usar essa alcunha, uma vez que poderia ser depreciado. Péricles juntara a seu círculo também filósofos, escultores, músicos, médicos, etc. Enfim, juntara todos aqueles que gozassem de algum saber (CAPIZZI, 2017) ${ }^{4}$.

A primícia da chegada dos vários sofistas pode ser observada na presença de Górgias, como nos conta Capizzi (2017, p. 85):

A confluência dos sofistas pra a Ática começou logo que a cidade de Leontino, na Sicília, ameaçada pelo poderio de Siracusa, enviou em 427 a Atenas, com a qual havia estipulado um tratado de aliança, uma missão diplomática conduzida por Górgias, já célebre e idoso, o qual deslumbrou o povo ateniense com o esplendor de sua fala.

Com efeito, a figura sábia e tenaz de Górgias terá como foco a ideia de convencer seu público de que qualquer tese pode ser demonstrada pela retórica e seu elemento poderoso de persuasão, desde profusos encômios a figuras condenadas pela cultura grega, como o caso de Helena no seu Encômio de Helena, até a inexistência da realidade no seu pungente Tratado do não-Ser. Em consequência disso, aquele que deseja capitular o interlocutor no tribunal deve confiar na escola dos retóricos, que ele se apresenta como um referente.

O sofista Górgias, no diálogo homônimo de Platão, ao ser questionado por Sócrates sobre que tipo de arte detinha o poder, responde que

4 Interessante notar que Capizzi (2017) afirma que, apesar de conviver no círculo de Péricles, um ambiente rico em trocas culturais, polêmicas entre filósofos (buscando saber pelo saber) e sofistas (buscando saber para fazer) eram inexistentes. Mesmo após o decênio da morte de Péricles e do crescimento de Alcibíades, os filósofos e sofistas se dedicavam a coisas diferentes, mas não se confrontavam. 
alberga a Retórica ${ }^{5}$. Tomando para si a adjetivação de um bom rétor, logo em seguida (449a-b). Adiante, quando convidado a responder qual o cerne do conhecimento da Retórica, o grande sofista prontamente responde que esta tem poder sobre os discursos (449d-e). E, mais à frente, Górgias afirma que os discursos aos quais a Retórica abarca são aqueles capazes de produzir persuasão $(\pi \varepsilon \bullet \theta \omega)^{6}$, sobretudo no ambiente das altercações públicas (452e-453a) ${ }^{7}$. Podemos, assim, compreender que, de acordo com a definição do sofista, a Retórica é a arte dos discursos persuasivos à qual ele detinha com maestria, conduzindo uma psicagogia - condução das almas. Guthrie (1995, p. 253) expõe que Górgias “[...] viu o poder de persuasão como o principal em todo campo, no estado da natureza e em todos os assuntos filosóficos, não menos que nos tribunais e na arena política", ampliando o raio de ação da Retórica.

Vemos com isso que Górgias de Leontinos jactava-se de deter

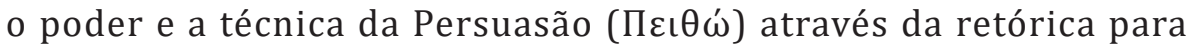
conduzir não apenas uma pessoa, mas até o público como um todo, mobilizando todo o seu conhecimento. Mas quais os caminhos que o Leontino propunha para ter êxito em sua psicagogia? Em outras

5 Górgias, 449a. É bastante conhecida a proposição de Schiappa (1999, p.14) sobre o passo 448d, no qual aparece, pela primeira vez, a palavra retórica no diálogo, aduzida pelo estudioso como a primeira vez que ela é utilizada, sendo, com isto, uma cria do gênio platônico.

6 Para Aristóteles, em livro homônimo, a Retórica é “[...] a faculdade de observar, em cada caso, o que este encerra de próprio para criar persuasão. Nenhuma outra arte possui tal função" (1355b25-30).

7 "[...] GOR: A meu ver, ser capaz de persuadir mediante o discurso os juízes no tribunal, os conselheiros no Conselho, os membros da Assembleia na Assembleia e em toda e qualquer reunião que seja uma reunião política. Ademais, por meio desse poder, terás o médico como escravo, e como escravo o treinador. Tornar-se-á manifesto que aquele negociante negocia não para si próprio, mas para outra pessoa, para ti, que tens o poder de falar e persuadir a multidão.

SOC: Agora sim, Górgias, tua indicação parece-me muito mais propínqua à qual arte consideras ser a retórica, e se compreendo alguma coisa, afirmas que a retórica é artífice da persuasão, e todo o seu exercício e cerne convergem a esse fim. Ou tens algo mais a acrescentar ao poder da retórica, além de incutir na alma dos ouvintes a persuasão?

GOR: De forma alguma, Sócrates; essa definição me parece suficiente, pois esse é seu cerne. [...]".

Revista Páginas de Filosofia, v. 9, n. 2, p. 5-17, jul.-dez. 2020 
palavras, há um caminho necessário para ocorrer a persuasão? Ao perscrutar o diálogo Górgias, de Platão, compreendemos que nele há elementos que o Leontino aduz como necessários para a ocorrência de uma psicagogia com êxito.

Conquanto, devemos notar que os elementos encontrados na obra platônica em questão, que traçaremos como via à persuasão, já eram difundidos com tal intento pelos retores anteriores a ela.

\section{KAIRóS: O RECONHECIMENTO DO TEMPO oportuno para a persuasão.}

Eric Charles White (1987) aponta que ao largo do contexto fi-

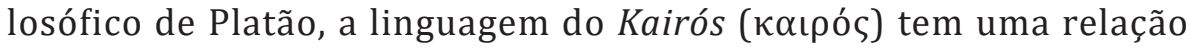
nas artes do arco e flecha e da tecelagem. No arco e flecha, o kairós relaciona-se à abertura pela qual a flecha do arqueiro deve passar, ao passo que na tecelagem, corresponde à abertura momentânea pela qual a lançadeira do tecelão deve passar. Com isto, percebe-se que o uso do Kairós em cada uma dessas artes implica em uma dificuldade, uma vez que o momento correto aparece e desaparece rapidamente ${ }^{8}$. Ademais, a abertura é estreita, não deixando uma significativa margem de erro. Assim, quem pretende desenvolver o Kairós deve praticar durante anos até que se especialize 9 .

Nos dois sentidos expostos acima, reconhecemos o Kairós como um tempo oportuno, não estático, mas fluido, no qual o observador deve articular uma série de conhecimentos empíricos para saber conduzir numa miríade de situações possíveis. Como podemos perceber pela designação, o Kairós é o tempo aberto à ação e constituído pela ocasião, tempo perigoso, caótico e indomável. Na cultura grega, o termo fora utilizado em diferentes campos do saber. No aspecto religioso, Kairós e Kronos, irmãos, dotavam de características opostas. Enquanto Kronos era controlável, divisível e regular, seu

8 Sobre isto, nos diz Doherty (1994, p. 12): "em ambos os sentidos, um artesão deve agarrar o momento crucial num desempenho de precisão e habilidade para atingir um objetivo".

9 Interessante observar que Cassin (2005) aponta que o kairós é uma palavra intraduzível de forma satisfatória, e tem por base o corpus hipocrático de um lado, e a poesia pindárica de outro, bem próprio da temporalidade sofística. 
irmão se apresentava como heterogêneo, intempestivo. Nos domínios técnicos, o Kairós era utilizado tanto na medicina, para discorrer sobre o momento crítico em que se saberia se um paciente iria curar-se ou morrer, quanto nas artes militares, para analisar o momento certo de uma investida, e na escultura, para delimitar aquela porção diminuta que garantiria que a obra sairia como pretendida. Como podemos notar, a chegada do kairós à discussão retórica será permeada por esse traço histórico do termo.

De acordo com Romeyer-Dherbey (1986, p. 49), o Górgias histórico foi o primeiro a reconhecer que assim como o tempo é descontínuo e apresenta ocasiões favoráveis e desfavoráveis à ação nos outros campos do saber, também o seria na retórica, de modo prático. 0 sofista Górgias é colocado então como o primeiro problematizador da questão no cerne da retórica, embora não o tenha estudado a fundo. Afinal, desenvolver um estudo completo e satisfatório de um termo que lhe é ausente qualquer delimitação hermética, sendo sobretudo o resultado da interferência mútua de diversos fatores que compõem cada momento singular, não foi tarefa de nenhum pensador, como aduz Dioniso de Halicarnasso ${ }^{10}$. Ainda assim, o intento de Górgias o fez argumentar sobre a utilização do kairós na fluidez dos ambientes políticos, uma vez que a ciência política se perfaz na oportunidade que se apresenta. Como aponta Romeyer-Dherbey (1986), Górgias conclui que o valor da ação política é a arte de observar a ocasião oportuna. Isso não quer dizer que Górgias definira o kairós com caráter meramente oportunista, mas que ela é uma ferramenta do homem sábio e prudente, que tem por ideal transformar a vida moral em algo praticável no tempo que se apresenta, tornado a virtude eficaz ${ }^{11}$. 0 kairós se torna, com isto, essencial a uma vida ética, na qual o que mais interessa é o estudo das conjunturas concretas.

${ }^{10}$ GÓRGIAS. Górgias, testemunhos e fragmentos. Lisboa, Colibri, 1993 p. 60.

${ }^{11}$ Verifica-se assim o comentário de Romeyer-Dherbey (1986, p. 50): “Definir a virtude segundo o kairós é exprimir a variação da excelência de acordo com os diferentes estados do sujeito moral: uma será a excelência da criança e outra a do velho, do cidadão e não-cidadão, do homem em tempo de guerra e do homem em tempo de paz $[\ldots]$... 


\section{HOMOLOGHIA: O CONSENSO COMO \\ INSTRUMENTO DE PERSUASÃO}

Uma análise acurada da obra platônica exige o debruce constante em suas linhas e, quase sempre que se perceba em um passo a conexão para uma ideia, que se desvela nas nuances em várias partes do mesmo diálogo ou mesmo do corpus platônico. É o que percebemos ao nos depararmos com o seguinte trecho no Górgias (487e5-6): “[...] 0 meu e o teu consentimento, portanto, serão realmente a completude da verdade [...]". A frase é dirigida à Calicles ${ }^{12}$, no trecho do diálogo em que ambos estão deliberando sobre que tipo de vida é preferível viver, se a dos que gozam de poder e cometem injustiça ou a dos que sofrem a injustiça. Entretanto, o elemento que nos chama atenção no passo é o termo ò $\mu$ o $\lambda$ oYía (homologhia) [consenso], aduzido por Sócrates como prova da verdade.

Percebemos que em vários momentos do diálogo Górgias, Sócrates, que procura persuadir seus interlocutores recalcitrantes dos argumentos que pressupõe estarem dotados de verdade, procura estabelecer um consenso entre si e com quem está falando no momento. Podemos, com isto, evidenciar que o próprio Platão reconhece que uma persuasão prolífica precisa ser homologada pelas partes do diálogo.

Casertano (2010) afirma que o estabelecimento de um consenso com o interlocutor é um aspecto da metodologia socrática. Com efeito, Sócrates procura estabelecer constantemente esse aspecto na obra Górgias, a começar com o personagem que dá nome ao diálogo, como explícito no passo 449a6, quando Sócrates pergunta a Górgias se de rétor é que ele deve ser chamado. Nos passos que se seguem, Sócrates quer delimitar a que arte o rétor alberga pertencer, como já vimos acima, e procura fazer comparativos com as demais artes. Neste ínterim, Sócrates conduz sempre seu discurso a fim de que Górgias vá concordando com ele, com o intuito de garantir a validade do que afirma ${ }^{13}$. Podemos considerar assim, que a homologhia é um importante

12 Personagem de grande importância no diálogo platônico, geralmente interpretado pelos comentadores como sendo o verdadeiro algoz de Sócrates no diálogo.

13 Durante todo o diálogo entre Sócrates e Górgias - 449d-461a - percebe-se que Sócrates vai desenvolvendo uma argumentação que exige respostas curtas, geralmente afirmativas, que vão conduzindo a anuência de Górgias às proposições engendradas por ele. 
recurso para o elenchus socrático, elemento este já também aduzido pelo próprio Leontino em outras partes do diálogo.

\section{Philia: A PERSUASão através da Amizade.}

Na cultura ocidental, a palavra philia $(\varphi \iota \lambda \iota \alpha)$ geralmente é traduzida pela palavra "amizade". Entretanto, a utilização dessa palavra tinha uma conotação semântica muito mais ampla em idos da Grécia Arcaica. Poderia ser empregado para explicar um forte vínculo de união ou de interesse entre os homens, que fossem advindos de uma mútua simpatia, de uma concordância de interesses, ou mesmo do mero acaso. Por isso, eram dotados de philia $(\varphi \iota \lambda \iota \alpha)$ os companheiros de jogo, de navegação, de viagem, de exército, os associados de comércio, os pais, irmãos, parentes e cidadãos da mesma pólis, em geral. 0 valor da philia $(\varphi \iota \lambda \iota \alpha)$ era enaltecido nos poemas e era um dos mais prestimosos vínculos que reuniam os homens, em forma de organizações como família, escolas filosóficas e grupos políticos. Vemos com isso que o termo philia $(\varphi \iota \lambda \iota \alpha)$ era vasto e compunha uma miríade de relação. De acordo com Rocha (2006), mesmo nos textos filosóficos da Grécia Clássica, inclusive os de Platão, não havia uma distinção clara entre o termo eros (amor) e philia (amizade) ${ }^{14}$.

Até o século V. a.C, como afirmam Gauthier e Jolif (1959), o

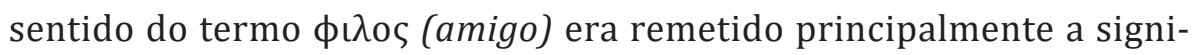
ficação jurídica. 0 termo possuía um caráter de possessividade em sua significação. Sendo assim, a esposa era "amiga" do homem, pois ele a levava para casa e ela lhe pertencia. Aos poucos, esse sentido jurídico foi dando lugar ao aspecto mais psicológico e afetivo. Nesse novo contexto, o termo $\phi \mathbf{\iota} \lambda \mathrm{o}$ s passou a ser atribuído às pessoas em termos de sua amabilidade e bondade.

Imbuídos dessa última acepção do termo philia $(\varphi \iota \lambda \iota \alpha)$, pretendemos analisar como Górgias o considera um elemento

14 Rocha aponta que há uma ambiguidade semântica na empregabilidade dos termos eros e philia em Platão. Ele observa que, embora o diálogo Lisis tenha por subtítulo "sobre a amizade", seu ponto de partida é o amor apaixonado entre Hipótales e Lisis. Não conseguindo distinguir de forma satisfatória o amor da amizade, Platão termina o diálogo fazendo Sócrates dizer que não sabe o que é a amizade, e abriu caminho para a discussão sobre o eros no Banquete. (2006, p. 67). 
necessário para o sucesso da persuasão, apesar dele estar ausente no diálogo Górgias. Todas as vezes em que há a menção do termo, o tom é claramente irônico da parte que argue ${ }^{15}$. Casertano (2010) compreende que, para que haja uma persuasão prolífica, se faz necessária amizade entre quem está dialogando, entre os interlocutores. Na verdade, os interlocutores do Górgias não são amigos, mostram-se como detentores de conceitos diferentes em relação ao que propõem e são opostos em relação ao entendimento do que é viver e a vida. A atmosfera do diálogo é marcada pela total incompatibilidade entre os interlocutores, veladas por uma série de cordialidades e cortesia. Por isso mesmo, entendemos que Platão determina que o sentimento compartilhado de philia $(\varphi \iota \lambda \iota \alpha)$ é um abridor de caminhos, não só quanto ao sentimento compartilhado, mas também pela abertura intelectual conduzida pela mesma afetividade. 0 mestre ateniense coloca essa necessidade - a da amizade - tanto na voz de Sócrates, seu personagem porta-voz, quanto nas vozes dos interlocutores, dentre eles, Górgias. Podemos, então, inferir que o Leontino também considerava o elemento da Philia como assaz necessária para a persuasão ${ }^{16}$.

\section{Conclusão}

Neste artigo procuramos refletir sobre um novo olhar que se faz necessário ter sobre os Sofistas. Personagens injustiçados pela história da filosofia, considerados algozes de filósofos. Vimos que há um conjun-

15 447b1-2 quando Querofonte diz que por Górgias ser seu amigo o fará uma exibição, tal qual tinha feito há pouco; 470c7-9 ao Sócrates chamar Polo de amigo, quando este diz que até uma criança o refutaria; $473 \mathrm{a} 3$ em que, à observação de Polo de que Sócrates só diz o absurdo, Sócrates responde que tentará fazê-las dizer também a Polo, uma vez que o considera um amigo; 485e na medida em que Cálicles, apesar de estar afirmando sobre os perigos que é um homem de idade seguir a filosofia, afirma que nutre uma amizade por Sócrates; 499c ao passo em que Sócrates está reclamando da mentira que Cálicles acabara de contar, na qual ele jamais esperava ser enganado voluntariamente por ele.

16 Importante notar aqui que, apesar do Górgias do diálogo homônimo de Platão, ser uma construção metodológica de sua figura contraparte, devemos considerar que o ateniense se valeu de elementos verdadeiros sobre o Leontino. Por isto, nos permite compreender que os caminhos para a Persuasão e Psicagogia encontrados na obra Platônica correspondem aos caminhos que o verdadeiro Górgias considerava.

Revista Páginas de Filosofia, v. 9, n. 2, p. 15-17, jul.-dez. 2020 
to considerável de pesquisadores que procuram recolocar os sofistas no campo do saber filosófico. Centramos a reflexão no maior expoente do sofismo, Górgias de Leontino, ancorado - sobretudo - no texto do corpus platônico. Compreendemos que os sofistas têm elementos e práticas que nos permitem inseri-los numa teoria do conhecimento densa, sólida e antropológica. Utilizando os caminhos da persuasão Kairós,Homologhia e Philia -, observamos que o Leontino propõe uma psicagogia, ou seja, a condução, através da retórica das "almas" dos interlocutores, seja um ou muitos. Entendemos, assim, que para fazer justiça, devemos colocar os sofistas como detentores de uma prática de elaboração de conhecimento, bastante relevante para a pragmática da democracia grega.

\section{REFERÊNCIAS}

CASERTANO, G. Os paradigmas da verdade em Platão. São Paulo: Edições Loyola, 2010.

CASSIN, B. 0 efeito sofístico. São Paulo: Editora 34, 2005.

DOHERTY JUNIOR, M. E. Cyberwrite and "Audience Acessed": Kairos Comes Online in the Composition Classroom. Dissertação de Mestrado não publicada para Bowling Green StateUniversity, 1994.

GAUTHIER, R. A.; JOLIF, J. L' Éthique à Nicomaque. Introduction, traduction etcommentaire. In: L'antiquité classique, Tome 29, fasc. 2, 19, 1959.

GÓRGIAS. Testemunhos Fragmentos. Lisboa: Edições Colibri, 1993.

GUTHRIE, W. Os Sofistas. 2. ed. São Paulo: Paulus, 2007.

JAEGER, W. W. Paideia: a formação do homem grego. 3. ed. São Paulo: Martins Fontes, 1994.

KAHN, C. H. Plato and the Socratic Dialogue: The Philosophical Use of Literary Form. Cambridge University Press, 1998.

KERFERD, G. B. O Movimento Sofista. São Paulo: Edições Loyola, 2003.

LAÊRTIOS, D. Vida e Doutrina dos Filósofos Ilustres. 2. ed. Brasília: Editora Universidade de Brasília, 2008.

MARQUES, M. P. (ORG.). Filosofia dos Sofistas: Hegel; Sdgwick; Versényi; Capizzi. São Paulo: PAULUS, 2017. 
PLATÃO. Górgias. São Paulo: Perspectiva\FAPESP, 2011.

Górgias, ou a Oratória. São Paulo: Difusão Europeia do Livro.

ROCHA, Z. 0 amigo, um outro si mesmo: a Philia na metafísica de Platão e na ética de Aristóteles. In: Psichê. São Paulo, Ano X, N. 17, p. 65-86. jan. 2006.

ROMEYER-DHERBEY, G. Os Sofistas. Lisboa: Edições 70, 1973.

SCHIAPPA, E. The Beginnings of Rhetorical Theory in Classical Greece. Londres: Yale University Press, 1999.

UNTERSTEINER, M. A obra dos Sofistas: uma interpretação filosófica. São Paulo: Paulus, 2012.

WHITE. E. C. Kaironomia: On the Will-to-Invent. Ithaca, NY: Cornell University Press, 1987.

Revista Páginas de Filosofia, v. 9, n. 2, p. 15-17, jul.-dez. 2020 